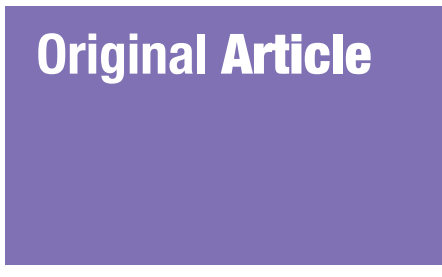

Submitted: 16 Aug 2015

Accepted: 20 June 2016

Online: 30 June 2016

\section{Thymectomy for Myasthenia Gravis: A 10-year Review of Cases at the Hospital Universiti Sains Malaysia}

\author{
Julieana Muhammed ${ }^{1,3}$, Chen $_{\text {Chui }}$ Yin $^{1,3}$, Wan Hazabbah WaN \\ HITAM $^{1,3}$, Mohamad Ziyadi GHAZALI ${ }^{2,3}$ \\ Department of Ophthalmology, School of Medical Sciences, Universiti Sains \\ Malaysia Health Campus, 16150 Kubang Kerian, Kelantan, Malaysia \\ 2 Department of Surgery, School of Medical Sciences, Universiti Sains Malaysia \\ Health Campus, 16150 Kubang Kerian, Kelantan, Malaysia
}

3 Hospital Universiti Sains Malaysia, 16150 Kubang Kerian, Kelantan, Malaysia

To cite this article: Muhammed J, Chen CY, Wan Hitam WH, Ghazali MZ. Thymectomy for Myasthenia Gravis: A 10-year review of cases at the Hospital Universiti Sains Malaysia. Malays J Med Sci. 2016; 23(4):71-78. doi: 10.21315/mjms2016.23.4.10

To link to this article: http://dx.doi.org/10.21315/mjms2016.23.4.10

\title{
Abstract
}

Background: A thymectomy is considered effective for patients with myasthenia gravis (MG). Although a few studies have described the role of a thymectomy in the treatment of MG in Asians countries, there are no published data on the application of this surgical approach for MG in Malaysia. We aimed to describe the clinical outcomes of MG patients who underwent a thymectomy and the factors affecting these outcomes.

Methods: This was a retrospective study involving 16 patients with MG who underwent a thymectomy at the Hospital Universiti Sains Malaysia (HUSM) from January 2002 until December 2012, with a follow-up period ranging from 3-120 months.

Results: The study consisted of 16 patients aged 22-78 years, 10 of whom were males. The overall remission/improvement rate was $87.5 \%$, and the rate of clinical outcomes classified as unchanged/ worsened was 12.5\%. Thymomamatous or non-thymomamatous MG, histology features, Osserman stage and the duration of follow-up were not significant prognostic factors. Post-operative mortality was $6.2 \%$ (1 of 16 patients died of septic shock).

Conclusion: A thymectomy seems to be an effective treatment for MG, with low surgical morbidity. Patients with a lower Osserman stage and those with/without thymomas had favourable outcomes.

Keywords: myasthenia gravis, thymectomy, treatment outcomes

\section{Introduction}

Myasthenia gravis (MG) is an autoimmune disease, with a wide range of clinical symptoms, ranging from mild weakness to severe debilitating respiratory failure. It is caused by impaired neuromuscular transmission due to antibodies present at the neuromuscular junction (1). A thymectomy, together with a combination of corticosteroids, immunosuppressive agents and anticholinesterase agents, have been shown to be effective treatments for MG, with better results reported compared to those of patients who received medical treatment only (2). There are limited data on surgical (thymectomy) and non-surgical treatment outcomes of $\mathrm{MG}$ patients in Malaysia. Thus, the aim of this study was to describe the clinical outcomes following thymectomies in a series of $16 \mathrm{MG}$ patients and the factors associated with their post-operative outcomes.

\section{Patients and methods}

This was a retrospective review of the clinical outcomes of 16 patients who had undergone an extended thymectomy for MG at the Hospital 
Universiti Sains Malaysia (HUSM) from January 2002 until December 2012 (Table 1). The followup period ranged from 3 months to 10 years.

Patients who were included in the study fulfilled the following criteria:

a) Patients with or without thymomas (based on computed tomography findings)

b) Patients with severe and generalised MG

c) Patients with long-standing MG and symptoms not controlled with oral medication

Patients were excluded if the thymectomy had been performed for other reasons (e.g. a mediastinal mass or an abscess).

A neurologist and cardiothoracic surgeon evaluated each patient prior to the surgical intervention. The Osserman classification was used for staging: stage I is ocular myasthenia; stage IIa is mild generalised MG; stage IIb is moderately severe MG, with bulbar involvement; stage III is acute fulminating myasthenia, with respiratory crises; and stage IV is late severe myasthenia (3).

All 16 patients had undergone an extended thymectomy through a median sternotomy. The clinical outcomes were evaluated based on the patient's symptoms and changes in medication. The outcomes were further classified as follows:

a) Remission: asymptomatic, with no medication required

b) Improvement: improvement of symptoms, with reduced medications

c) Unchanged: no change in symptoms and medications

d) Worsened: worsening of symptoms and increase in medication requirements

The data were analysed using the Statistical Package for Social Sciences, version 20.0 (SPSS Inc., Chicago, IL, USA). The results are presented as frequencies and percentages. The median and interquartile range (IQR) are used for descriptive statistics. The non-parametric Fisher's exact test and Mann-Whitney test were used to compare the outcomes between the remission/improvement groups and no change/worsened groups with regard to the histology of the resected thymus gland, Osserman classification and follow-up time. For all analyses, the level of statistical significance was defined as a $p$ value of $<0.05$.

Table 1: Summary of clinical course of 16 patients in this study

\begin{tabular}{llllllll}
$\begin{array}{l}\text { Patient } \\
\text { No. }\end{array}$ & $\begin{array}{l}\text { Age } \\
\text { (year) }\end{array}$ & Race & Sex & $\begin{array}{l}\text { Duration } \\
\text { of } \\
\text { symptoms } \\
\text { (months) }\end{array}$ & $\begin{array}{l}\text { Osserman } \\
\text { classification }\end{array}$ & $\begin{array}{l}\text { Histopathological } \\
\text { study }\end{array}$ & Outcome \\
1 & 37 & Malay & Female & 3 & III & Thymoma & Improvement \\
2 & 22 & Chinese & Male & 4 & IIb & Hyperplasia & Improvement \\
3 & 75 & Malay & Male & 8 & III & Hyperplasia & Worsened \\
4 & 48 & Malay & Female & 60 & IV & Thymus & No change \\
5 & 37 & Malay & Male & 60 & IV & Hyperplasia & Improvement \\
6 & 32 & Malay & Female & 72 & IIb & Hyperplasia & Improvement \\
7 & 47 & Malay & Male & 18 & IIb & Hyperplasia & Improvement \\
8 & 45 & Chinese & Male & 120 & IIa & Hyperplasia & Improvement \\
9 & 36 & Malay & Female & 9 & IIa & Hyperplasia & Improvement \\
10 & 49 & Malay & Male & 3 & III & Hyperplasia & Remission \\
11 & 38 & Malay & Female & 2 & IIa & Thymus & Improvement \\
12 & 25 & Malay & Male & 10 & IIa & Hyperplasia & Improvement \\
13 & 56 & Chinese & Male & 10 & IIa & Thymoma & Remission \\
14 & 40 & Malay & Male & 7 & I & Thymoma & Improvement \\
15 & 58 & Malay & Male & 6 & IIa & Thymus & Improvement \\
16 & 26 & Malay & Female & 24 & IIa & Hyperplasia & Improvement \\
\hline
\end{tabular}




\section{Results}

The clinical symptoms of the majority of the patients with MG at the time of their initial presentation to the medical practitioner were limb weakness (87.5\%) and ptosis (81.3\%). Other symptoms were dysphagia (75\%), diplopia (43.8\%), respiratory crises (25\%), dysphonia (18.8\%) and chest pain (6.3\%) (Table 2).

Table 2: Clinical presentation of the patients with myasthenia gravis (MG) who underwent a thymectomy at the Hospital Universiti Sains Malaysia (HUSM)

\begin{tabular}{lll} 
Variables & $\begin{array}{l}\text { Number } \\
\text { of } \\
\text { patients } \\
(\mathbf{n = 1 6 )}\end{array}$ & $\begin{array}{l}\text { Percentages } \\
(\%)\end{array}$ \\
Ptosis & 13 & 81.3 \\
Limb weakness & 14 & 87.5 \\
Diplopia & 7 & 43.8 \\
Dysphagia & 12 & 75.0 \\
Dysphonia & 3 & 18.8 \\
Respiratory crises & 4 & 25.0 \\
Chest pain & 1 & 63.0 \\
\hline
\end{tabular}

Ten $(63 \%)$ of the patients were males, and six (37\%) were females. Most (81\%) were Malay, and a smaller percentage (19\%) was Chinese. There were no Indian, Siamese or other races in this study. The mean age at disease onset was 35.7 \pm 3.9 years (range, 18.0-74.0), with a median duration of symptoms (disease onset to time of the operation) of 10.0 months (range, 3.0-120).

The median length of follow-up was $33.8 \pm$ 8.7 months. There was no significant difference in the median follow-up between the remission and improvement group versus the unchanged and worsened group ( $p$ : 0.112; Table 3).

The histopathological study of the resected thymus glands revealed thymus hyperplasia in $12(75 \%)$ cases, thymomas in $3(18.7 \%)$ cases and normal thymic tissue in $1(6.3 \%)$ case (Figure 1). Although 11 (78.6\%) patients with thymus hyperplasia and all (21.4\%) the patients with thymomas showed remission and improvement, there was no statistical correlation between the histopathological findings and clinical outcomes ( $p$ : o.150; Table 3).

According to the Osserman classification, 7 patients (43.7\%) were stage IIa. One patient (6.3\%) had stage I disease, 3 patients (18.7\%) had stage IIb disease, 3 patients (18.7\%) had stage III disease, and 2 patients (12.6\%) had stage IV disease (Figure 2). All the patients with lower Osserman stages achieved remission or showed an improvement as compared to those with higher Osserman stages (grades III and IV). However, there was no statistical correlation between the Osserman stage and clinical outcomes ( $p$ : 0.225; Table 3).

All 16 patients received oral pyridostigmine pre-operatively, with median doses of $285 \mathrm{mg}$ per day. Three patients received pyridostigmine, prednisolone and azathioprine, one patient received pyridostigmine and a steroid, and one patient received pyridostigmine and azathioprine. One patient received intravenous immunoglobulin pre-operatively. Post-operatively, three patients continued to receive azathioprine and a reduced dose of pyridostigmine, and one patient required plasmapharesis due to worsening of symptoms. One patient required a low dose of prednisolone post-operatively.

In this study, there was one death following the thymectomy due to worsening of symptoms induced by sedation during anaesthesia. This patient succumbed to death on day 11 after the operation due to severe septic shock, secondary to fulminant chest infection. Two patients had minor anaesthesia-related complications, with atelectasis and mild pleural effusion. Both were treated with chest physiotherapy and monitored. One patient experienced mild chest pain and was treated with analgesia only. 
Table 3: Prognostic factors affecting clinical outcomes

\begin{tabular}{|c|c|c|c|}
\hline \multirow[t]{2}{*}{ Variables } & \multicolumn{2}{|l|}{ Outcome } & \multirow[t]{2}{*}{ P value* } \\
\hline & $\begin{array}{l}\text { Remission/ } \\
\text { improvements }\end{array}$ & $\begin{array}{l}\text { No change/ } \\
\text { worsened }\end{array}$ & \\
\hline $\begin{array}{l}\text { Histology of resected thymus gland } \\
(n=16)\end{array}$ & & & $0.150^{\mathrm{a}}$ \\
\hline Normal thymus tissue & o & 1 & \\
\hline Thymus hyperplasia & 11 & 1 & \\
\hline Thymoma & 3 & $\mathrm{O}$ & \\
\hline Osserman classification $(n=16)$ & & & $0.225^{\mathrm{a}}$ \\
\hline Stage I & 1 & $\mathrm{O}$ & \\
\hline Stage IIa & 7 & $\mathrm{O}$ & \\
\hline Stage IIb & 3 & $\mathrm{O}$ & \\
\hline Stage III & 2 & 1 & \\
\hline Stage IV & 1 & 1 & \\
\hline Follow-up time (median) & 34.5 & 7.5 & $0.112^{\mathrm{b}}$ \\
\hline
\end{tabular}

${ }^{*}$ Fisher's exact test, ${ }^{* b}$ Mann-Whitney test. Significant $P$ value $<0.001$

\section{Histology of resected thymus gland}

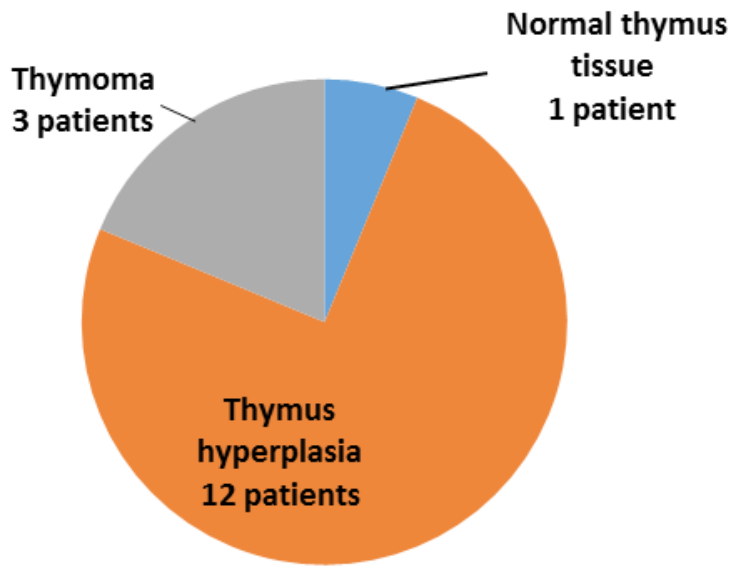

Figure 1: Histology of resected thymus gland 


\section{Ossermann classification}

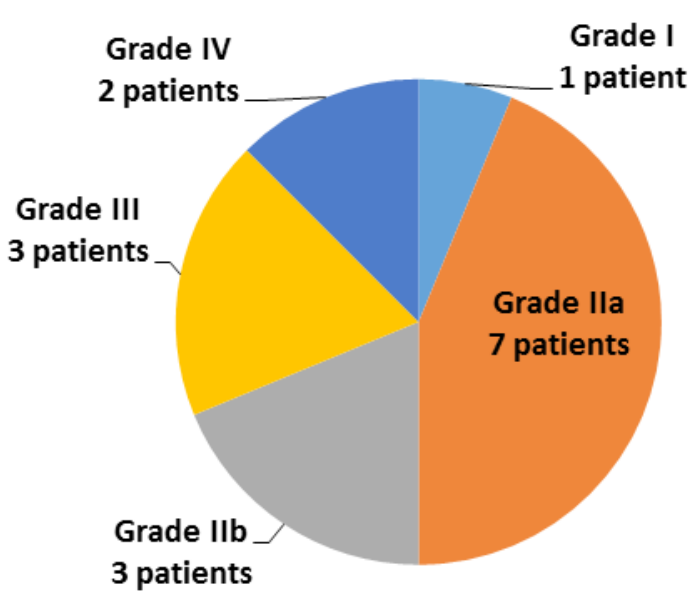

Figure 2: Osserman classification of the severity of myasthenia gravis (MG)

\section{Discussion}

Since Blalock et al. (4) first performed a thymectomy, with good outcomes, this procedure has been considered an effective treatment compliment to medical therapies. Previous studies reported improvement rates of $54-94 \%$ and remission rates of $13-46 \%$ following a thymectomy, making it the treatment of choice for MG $(5,6)$. Similarly, our study showed good clinical outcomes, with an overall remission/ improvement rate of 87.5 and a clinical unchanged/worsened rate of $12.5 \%$ (Figure 3 ). Despite the promising results observed in MG patients following a thymectomy, the selection of patients and specific indications for surgery remain unclear. Generalised disease, in addition to the severity of symptoms, response to medication, disease duration, and presence of a thymoma, are generally indications for this procedure (7).

About $90 \%$ of the local population in Kelantan is Malay, with the remaining made up of those of Chinese, Siamese and Indian descent. This demographic composition was reflected in the present study, where the majority of the patients were Malay, and the remainder were Chinese. In Kelantan, Indians are a minority group, and few cases are referred to the neurosurgical clinic in HUSM. No representatives from Indian population as they are a minority population with limited case were referred to neurosurgical clinic in HUSM. In contrast to previous studies, males were the dominant group in the present study. The atypical gender preponderance may have affected the clinical outcomes in this study, as a previous study found that female patients responded better than males (5). In contrast, another study found that gender did not affect clinical outcomes (8).

We found no statistically significant difference in the median follow-up of the remission/improvement group versus that of the unchanged/worsened group. Nieto et al. (8) reported that $46 \%$ of MG patients who underwent a thymectomy achieved complete remission in a 5-year follow-up study. Maggi et al. (9) reported a higher remission rate in a 5-10-year follow-up study of MG patients following a thymectomy. Similar to this finding, Stern et al. (10) reported high remission rates and symptom improvement in a follow-up study of over 10 years of MG patients following thymectomies. These findings suggest that the remission rates of the patients in the present study would likely increase in a longer-term follow-up study.

Approximately $10-15 \%$ of patients with MG have thymomas. According to one study, the prognosis of MG patients with thymomas was worse than that of MG patients with thymus hyperplasia (11). Hsu et al. (12) found that the possibility of a relapse of symptoms after a thymectomy was greater in patients with thymomas than in those without thymomas. In contrast, our study showed that all three patients who had a thymoma had good outcomes. Various histology findings have been reported to have an impact on post-thymectomy clinical 
outcomes. However, Tsinzerling et al. (13) found no significant differences in clinical outcomes according to histology results.

Due to the immunological role of the thymus in MG, complete removal of the thymus gland is crucial. The thymus gland arises from the third and fourth branchial arch. It migrates in a caudally manner, with scattered foci in mediastinal fat containing thymic tissue (14). The thymus gland believed to be a source of T-cells, which cause destruction of the anticholinesterase receptor, thereby producing muscle weakness in MG (15). There is no consensus on the role of surgery in the complete removal of the thymus gland and associated scattered foci in mediastinal fat. However, a previous study demonstrated excellent outcomes using an extended thymectomy and reported that it was suitable for both thymomatous and non-thymomatous patients (16). The transternal approach, with anterior mediastinal dissection, has been shown to be a good technique for ensuring the complete removal of thymus tissue. This technique was used in all the patients in the present study, and we demonstrated favourable outcomes, comparable to those of a previous study (16). Furthermore, a single surgeon performed all the operations, making the assessment of the outcomes more reliable. Research also reported promising outcomes following an extended thymectomy through the transcervical or transternal approach and a new approach via video-assisted thoracoscopic thymectomy (17). If it is not possible to remove the entire residual thymus gland using either of the aforementioned techniques, the patient will eventually relapse.

In common with the findings of a previous study, the Osserman classification of the MG patients was strongly associated with clinical outcomes in the present study. Ozdemir et al. (18) found a 7 -fold increased risk of clinical worsening in patients with stage IIb and III disease. Nieto et al. (8) found that patients with stage I and III disease had a better outcome than those with other stages. Similar to those findings, Venuta et al. (19) found that patients with a lower Osserman stage had favourable outcomes. In the present study, the clinical outcomes of the patients with stage I and II disease were better than those of the patients with other stages, but there was no statistically significant difference between the Osserman stage and clinical outcomes.

Controversy exists regarding the need for a thymectomy in ocular MG because $85-90 \%$ of cases will usually progress to generalised disease within 2 years (20). Masaoka et al. (15) found that a thymectomy was effective in treating ocular MG. However, Nakamura et al. (21) reported delayed remission after a thymectomy in a patient with pure ocular MG. Another study reported that the time to remission following a thymectomy was faster in patients with ocular MG who had a short

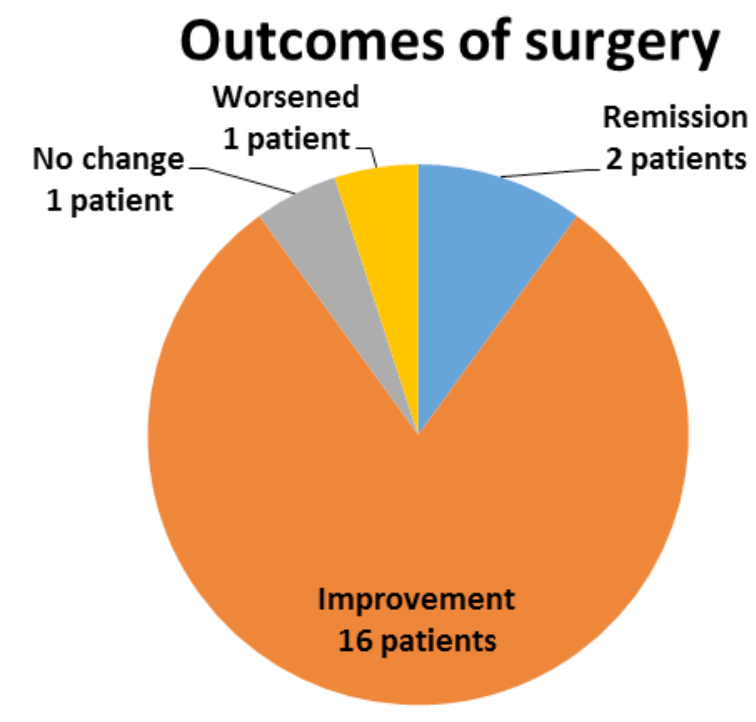

Figure 3: Outcomes of surgery 
Original Article | Thymectomy in Myasthenia Gravis

duration of illness (22). In our study, only one patient with ocular MG underwent a thymectomy. This patient's symptoms improved, and the patient required no drug therapy post-operatively in a follow-up of 40 months.

A thymectomy is considered a safe procedure, with low mortality and morbidity. In our study, only one patient died due to a myasthenic crisis, which was induced by sedation. This patient was 78 when diagnosed with Osserman stage III disease and a thymoma. Another study showed that older age at diagnosis and Osserman stage III and above were associated with a less favourable prognosis (23). Takanami et al. (24) found that the involvement of the bulbar muscle prior to surgery was a significant risk factor for a myasthenic crisis. A multi-centre follow-up study in Italy found that the following factors were associated with higher mortality rates: male, older than 40 years, a short history of disease and presence of a thymoma (25).

Our study has several limitations. First, this 10-year retrospective study might be biased due to missing data, especially on the symptoms of the patients, both pre- and post-operatively. Second, the sample size of the study was small. Thus, the non-significant ( $p$ values of $>0.05$ ) were expected in this small study. As the findings reflect those of a single institution review, they may not be transferable to the general population of $\mathrm{MG}$ patients in Malaysia who undergo thymectomies. Thus, a multi-centre study, with a larger number of patients will be a future aim. Future studies should also include the multi-ethnic Malaysian population.

\section{Conclusion}

A thymectomy seems to be an effective treatment for MG, with low surgical morbidity. This single-centre study showed that the majority of patients benefited from the thymectomy, with tremendous clinical improvements and drug reduction post-operatively. In the present study, ocular MG also improved post-operatively. To improve the power of the study and increase the generalisability of the results, multi-centre studies are needed in the future.

\section{Acknowledgements}

The results of this study have been presented as a poster at Malaysia-Singapore Joint Ophthalmic Congress 2013 .

\section{Conflict of Interest}

None

\section{Funds}

None

\section{Authors' Contributions}

Conception and design: JM, CCY

Analysis and Interpretation of the data: JM, CCY

Drafting of the article: JM, CCY

Critical revision of the article for important intellectual content: WHWH, ZMG

Final approval of the article: WHWH, ZMG

Provision of study materials or patients: ZMG

Collection and assembly data: JM, CCY

\section{Correspondence}

Professor Dr. Wan Hazabbah Wan Hitam

M.D (USM), M.Surg. (Ophthal) UKM,

Fellow of Neuro-ophthalmology TEI@NHG Singapore Department of Ophthalmology, School of Medical Sciences,

Universiti Sains Malaysia, 16150 Kubang Kerian, Kelantan, Malaysia

Tel: +6012-9833535

Fax: +09-7653370

E-mail: hazabbah@usm.my, hazabbah@yahoo.com

\section{References}

1. Lindstrom JM, Seybold ME, Lennon VA, Whittingham $\mathrm{S}$, Duane DD. Antibody to acetylcholine receptor in myasthenia gravis. Prevalence, clinical correlates, and diagnostic value. Neurology. 1976;26(11):10541059. doi: http://dx.doi.org/10.1212/o1. wnl.0000405029.20726.2c

2. Valli G, Jann S, Premoselli S, Scarlato G. Myasthenia gravis treatment: twelve years experience on 110 patients. Ital $J$ Neurol Sci. 1987;8(6):593-601. doi: http://dx.doi.org/10.1007/bfo2333667.

3. Osserman KE, Genkins G. Studies in Myasthenia Gravis. NY State J Med. 1961; 61: 2076-2085.

4. Blalock A, Mason MF, Morgan HJ, Riven SS. Myasthenia Gravis and tumors of the thymic region: Report of a case in which the tumor was removed. Ann Surg. 1939;110(4):544-561. doi: http://dx.doi. org/10.1097/00000658-193910000-00005.

5. Budde JM, Morris CD, Gal AA, Mansour KA, Miller JI Jr. Predictors of outcome in thymectomy for myasthenia gravis. Ann Thorac Surg. 2001;72(1):197-202.

6. Nussbaum MS, Rosenthal GJ, Samaha FJ, Grinvalsky HT, Quinlan JG, Schmerler M, et al. Management of myasthenia gravis by extended thymectomy 
with anterior mediastinal dissection. Surgery. 1992;112(4):681-688.

7. Lanska DJ. Indications for thymectomy in myasthenia gravis. Neurology. 1990;40(12):1828-1829. doi: http://dx.doi.org/10.1212/wnl.40.12.1828.

8. Nieto IP, Robledo JP, Pajuelo MC, Montes JA, Giron JG, Alonso JG, et al. Prognostic factors for myasthenia gravis treated by thymectomy: review of 61 cases. Ann Thorac Surg. 1999;67(6): 1568-1571. doi: http:// dx.doi.org/10.1016/sooo3-4975(99)oo310-o.

9. Maggi G, Casadio C, Cavallo A, Cianci R, Molinatti M, Ruffini E. Thymectomy in myasthenia gravis. Results of 662 cases operated upon in 15 years. Eur $J$ Cardiothorac Surg. 1989;3(6):504-511.

10. Stern LE, Nussbaum MS, Quinlan JG, Fischer JE. Long-term evaluation of extended thymectomy with anterior mediastinal dissection for myasthenia gravis. Surgery. 2001;130(4):774-780. doi: http://dx.doi. org/10.1067/msy.2001.116674.

11. Tellez-Zenteno JF, Remes-Troche JM, García-Ramos G, Estanol B, Garduno-Espinoza J. Prognostic factors of thymectomy in patients with myasthenia gravis: a cohort of 132 patients. Eur Neurol. 2001;46(4):171177. doi: http://dx.doi.org/10.1159/000050800.

12. Hsu HS, Huang CS, Huang BS, Lee HC, Kao KP, Hsu WH, Huang MH. Thymoma is associated with relapse of symptoms after transsternal thymectomy for myasthenia gravis. Interact Cardiovasc Thorac Surg . 2006;5(1):42-46. doi: http://dx.doi.org/10.1510/ icvts.2005.116616.

13. Tsinzerling N, Lefvert AK, Matell G, PirskanenMatell R. Myasthenia gravis: a long term followup study of Swedish patients with specific reference to thymic histology. J Neurol Neurosurg Psychiatry.2007;78(10):1109-1112. doi: http:// dx.doi.org10.1136/jnnp.2006.109488.

14. Masaoka A, Nagaoka Y, Kotake Y. Distribution of thymic tissue at the anterior mediastinum. Current procedures in thymectomy. $J$ Thorac Cardiovasc Surg. 1975;70(4):747-754.

15. Masaoka A, Yamakawa Y, Niwa H, Fukai I, Kondo S, Kobayashi M, Fujii Y, Monden Y. Extended thymectomy for myasthenia gravis patients: a 20-year review. Ann Thorac Surg. 1996;62(3):853-859. doi: http://dx.doi.org/10.1016/sooo3-4975(96)oo376-1.
16. Wright GM, Barnett S, Clarke CP. Video-assisted thoracoscopic thymectomy for myasthenia gravis. Intern Med J. 2002;32(8):367-371. doi: http:// dx.doi.org/10.1046/j.1445-5994.2002.00251.x.

17. Ozdemir N, Kara M, Dikmen E, Nadir A, Akal M, Yucemen $\mathrm{N}$, et al. Predictors of clinical outcome following extended thymectomy in myasthenia gravis. Eur J Cardiothorac Surg. 2003;23(2):233-237. doi: http://dx.doi.org/10.1016/s1010-7940(02)00744-3.

18. Venuta F, Rendina EA, De Giacomo T, Della Rocca G, Antonini G, Ciccone AM, et al. Thymectomy for myasthenia gravis: a 27-year experience. Eur $J$ Cardiothorac Surg. 1999;15(5):621-625. doi: http:// dx.doi.org/10.1016/s1010-7940(99)00052-4.

19. Gilbert ME, De Sousa EA, Savino PJ. Ocular Myasthenia Gravis treatment: the case against prednisone therapy and thymectomy. Arch Neurol. 2007;64(12):1790-1792.

20. Roberts PF, Venuta F, Rendina E, De Giacomo T, Coloni GF, Follette DM, et al. Thymectomy in the treatment of ocular myasthenia gravis. $J$ Thorac Cardiovasc Surg. 2001;122(3):562-568. doi: http:// dx.doi.org/10.1067/mtc.2001.116191.

21. Nakamura H, Taniguchi $\mathrm{Y}$, Suzuki $\mathrm{Y}$, Tanaka $\mathrm{Y}$, Ishiguro K, Fukuda M, et al. Delayed remission after thymectomy for myasthenia gravis of the purely ocular type. J Thorac Cardiovasc Surg. 1996;112(2):371375. doi: http://dx.doi.org/10.1016/so022-5223 (96)70264-7.

22. Mussi A, Lucchi M, Murri L, Ricciardi R, Luchini L, Angeletti CA. Extended thymectomy in myasthenia gravis: a team-work of neurologist, thoracic surgeon and anaesthesist may improve the outcome. Eur $J$ Cardiothorac Surg. 2001;19(5):570-575. doi: http://dx.doi.org/10.1016/s1010-7940(01)oo634-o.

23. Remes-Troche JM, Tellez-Zenteno JF, Estanol B, Garduno-Espinoza J, Garcia-Ramos G. Thymectomy in myasthenia gravis: response, complications, and associated conditions. Arch Med Res. 2002;33(6):545-551.

24. Takanami I,Abiko T, Koizumi S. Therapeutic outcomes in thymectomied patients with myasthenia gravis. Ann Thorac Cardiovasc Surg. 2009;15(6):373-377.

25. Mantegazza R, Beghi E, Pareyson D, Antozzi C, Peluchetti D, Sghirlanzoni A, et al. A multicentre follow-up study of 1152 patients with myasthenia gravis in Italy. $J$ Neurol. 1990;237(6): 339-344.doi: http://dx.doi.org/10.1007/bfoo315656. 